\title{
Researching the enacted mathematics curriculum: learning from various perspectives on enactment
}

\author{
Denisse R. Thompson • Mary Ann Huntley
}

Accepted: 19 August 2014 / Published online: 29 August 2014

(C) FIZ Karlsruhe 2014

\begin{abstract}
This issue of $Z D M$ focuses on research related to the enacted curriculum from various perspectives within the context of the US educational system. In this editorial, we describe the broad view of curriculum enactment taken in this issue, highlighting that we mean more than just how instruction plays out within a classroom. For instance, enactment can occur at a national level as educational goals are enacted into a set of national objectives or standards. Enactment can occur as goals or standards are embedded into written curriculum materials or textbooks, both in terms of teacher guides and materials for students. Enactment can occur as teachers make decisions about how to use their written curriculum materials. Finally, enactment can occur as teachers and students engage and interact with written materials during classroom instruction. We elaborate briefly on these views and then outline the structure of this $Z D M$ issue.
\end{abstract}

Keywords Curriculum enactment $\cdot$ Mathematics curriculum $\cdot$ Textbook research

\section{Introduction}

Throughout the world, textbooks play a major role in the educational system of countries. As noted by researchers

D. R. Thompson

College of Education, University of South Florida, 4202 E.

Fowler Ave., STOP EDU105, Tampa, FL 33620, USA

e-mail: denisse@usf.edu

M. A. Huntley $(\bowtie)$

Department of Mathematics, Cornell University, Ithaca, NY

14850, USA

e-mail: huntley@math.cornell.edu affiliated with the Trends in International Mathematics and Science Study (TIMSS), "Perhaps only students and teachers themselves are a more ubiquitous element of schooling than textbooks. ... They represent school disciplines to students. They translate a country's curriculum policies into such representations" (Valverde et al. 2002, p. 1). Given the central role of textbooks in shaping and facilitating education, it seems only natural that educators are interested in researching various aspects of textbooks and their use. Indeed, as noted by Fan (2013), research about school textbooks has increased internationally in the last few decades and represents an important area for scientific research. This journal, itself, has recognized the importance of textbook research, with an issue on this topic as recently as volume 45, issue 5, in Fall 2013.

In Fall 2010, a conference on researching the enacted mathematics curriculum that was funded by the US National Science Foundation was held in the in Tampa, FL (US). This conference brought together veteran curriculum scholars, relatively new researchers, and doctoral students to begin discussing a conceptual model for researching curriculum enactment. That conference led to a book, Enacted Mathematics Curriculum: A Conceptual Framework and Research Needs (Thompson and Usiskin 2014), to share the findings and discussions of the conference with a larger audience. But we believed there was still more to share. Although the book expanded on the work of the conference, many conference participants had research results related to curriculum enactment that needed to be shared. Hence, this issue of $Z D M$ is one means of sharing that research with a wide international audience.

As previously noted, interest in textbook research and enactment of textbook curricula has been expanding throughout the world. In addition to the issue of $Z D M$ in 2013, an international conference on mathematics textbook 
research was held in Southampton, England, in July 2014, as this $Z D M$ issue was being finalized. This conference was attended by over 150 scholars from at least 30 countries. Moreover, another international conference on mathematics curriculum is planned for November in Chicago, IL (US), focusing on aspects of digital curriculum. All of these efforts testify to the interest and importance of textbook research by scholars from around the globe.

This issue continues this focus on textbook research, particularly on research related to the enacted curriculum from various perspectives within the context of the US educational system. In the US, considerable research related to curriculum has occurred since the late 1980s and early 1990s as curriculum materials, specifically textbooks, have been developed in response to the reform recommendations of the National Council of Teachers of Mathematics in its Curriculum and Evaluation Standards for School Mathematics (1989) and its revised Principles and Standards for School Mathematics (2000). In the era of curriculum reform in the late 1950s and early 1960s, Begle, a key figure in the School Mathematics Study Group (SMSG), reflected on the importance of textbooks: "The textbook has a powerful influence on what students learn. ... The evidence indicates that most student learning is directed by the text rather than the teacher. This is an important finding, since the content of the text is a variable that we can manipulate" (Begle 1973, p. 209). Many of today's curriculum developers also believe textbooks are an essential means to implement curriculum recommendations at district, state, or national levels so that teachers have instantiations of what those recommendations might look like for students (Hirsch 2007). But understanding how the textbook influences mathematics teaching and learning requires research from a number of perspectives, including how the textbook reflects the enactment of curriculum.

\section{What is meant by curriculum enactment}

Researchers in the Second International Mathematics Study (SIMS) identified three levels of curriculum: the intended curriculum reflected whether tested content was represented in official curriculum documents and related textbooks for use; the implemented curriculum focused on whether teachers had taught the content being assessed; and the attained curriculum focused on actual student achievement (Travers 1992). In TIMSS, this tri-partite model was expanded, with revised meanings attached to the original three levels and one additional curriculum level added. Valverde et al. (2002) indicate that the intended curriculum represents the objectives in national or official documents that are expected of all students. The implemented curriculum then focuses on how these objectives play out in classroom instruction as teachers and students interact to learn mathematics. The attained curriculum represents both the content that students have learned and the processes in which students engage. Between the intended and the implemented curriculum levels, TIMSS researchers inserted the potentially implemented curriculum of the textbook, recognizing that the textbook is a mediator between intentions and implementation (Robitaille et al. 1993; Schmidt et al.1997; Valverde et al. 2002).

Some curriculum researchers view curriculum enactment as somewhat synonymous with the implemented curriculum. However, in this issue, we take a broader view of curriculum enactment as involving more than just how instruction with a textbook or other set of curriculum materials is implemented within a classroom. For instance, the written curriculum of a textbook illustrates one instantiation or enactment of the curriculum as specified in standards documents or syllabi (Valverde et al. 2002). The assessed curriculum is an enactment by curriculum authors or policy makers of what concepts are most important for students to master. The teacher's intended curriculum is an enactment of the interactions of a written curriculum with a teacher's perceptions of what is important for students to learn and perceptions of what students are capable of learning. The implemented curriculum is the interaction of the written curriculum with the instruction that students experience. "At each stage of the process by which goals for education get transformed into the experiences of an individual learner there is the enactment of the principles of the previous stage - goals enacted into syllabi, syllabi enacted into materials, materials enacted into teaching, teaching of a class enacted into the activities and thoughts of an individual learner" (Usiskin, personal communication 2012). We consider each of these as an aspect of curriculum enactment, and, therefore, worthy of research.

\section{Structure of this ZDM issue}

As indicated in Sect. 2, we take a broad view of the term curriculum enactment, and this broad view is reflected in the papers within this issue. The introductory paper by Remillard and Heck (2014) outlines a conceptual model related to curriculum enactment. This conceptual model situates curriculum enactment within a broad educational system connecting policy, design, and enactment. Remillard and Heck also indicate where various papers in this issue fit within their model and may be useful in providing a means for scholars and researchers within different countries and different traditions to share a common language, or at least, to understand better the differences in how specific curriculum terms are used in different countries. Subsequent papers in this issue then demonstrate research 
on the different perspectives of curriculum enactment as indicated in Sect. 2 and within different components of the model articulated by Remillard and Heck (2014).

The next paper, by Confrey, Maloney, and Corley (2014), provides insight into how learning trajectories can be developed and associated with educational standards that are articulated at a national level. Learning trajectories provide possibilities for research into student learning, potential for influencing curricular design, and suggestions for classroom instruction.

The next two papers use detailed document analysis to determine how standards, as enacted within the design of written curriculum materials, have the potential to offer different opportunities for student learning. The paper by Remillard, Harris, and Agodini (2014) reports results from analysis of the materials accompanying elementary curricula, including teacher materials, in terms of mathematical emphasis, instructional approach, and teacher support. They consider how design differences in the materials may explain achievement differences observed during student testing. Huntley and Terrell (2014) conducted a detailed analysis of algebra textbooks or units in integrated textbooks to consider design issues related to the topics of one-step and multi-step linear equations. They consider the sequence of introduction of the topics, cognitive level in terms of performance expectation, and use of other resources such as manipulatives or technology to facilitate learning. They suggest that these differences potentially lead to different opportunities for student learning, although connections to actual student learning are an area that they suggest for further research.

The next two papers look at how the textbook is used within the context of geometry in secondary schools. Sears and Chávez (2014) investigate the opportunities that two different textbooks provide for students to engage with proof, considering how those differences facilitate the ways in which teachers enact proof tasks as part of their classroom instruction. The paper by Thompson and Senk (2014) focuses on how 12 teachers using the same textbook use it differently to provide varied opportunities for students to learn a geometry topic that is commonly found in textbooks around the world, namely congruence. They document differences in the percentage of lessons taught, percentage of homework questions assigned, and how teachers use features within the textbook lessons, such as interactive geometry software.

The paper by Hunsader and colleagues (2014) takes a slightly different approach to examining enactment of the written curriculum by analyzing the assessment instruments that accompany published curricula. They suggest that teachers and curriculum developers should be concerned not only with the content that students learn but also with how they learn that content, specifically with the opportunities that students have to demonstrate reasoning, communication, connections, use of graphics, or translation of representation. Their analysis of assessments provides evidence about the extent to which such processes are integrated into curricular assessments.

The paper by Otten and Soria (2014) focuses on the aspect of curriculum enactment that is consistent with what many consider when they think about enactment, namely actual classroom instruction. These authors document how four algebra tasks are addressed as part of classroom instruction, including the types of verbal discourse expected of students. In addition, Otten and Soria (2014) demonstrate how differences in enactment often result in differences in achievement.

The conceptual model and subsequent research papers were all written by US scholars within the US educational system. As many educators throughout the world know, the US does not have a national educational system; rather, education is a matter of local control and is under the purview of the 50 individual states. So, we were interested in the extent to which the conceptual model and the types of curriculum research done within the US context would be applicable and relevant to curriculum researchers in other countries. Consequently, we invited two international scholars, one from a European viewpoint and one from an Asian viewpoint, to each write a commentary about the model and related papers in the issue. These commentaries are the final two papers of this issue.

The commentary by Kaur (2014) focuses on comparisons and contrasts with the educational system in Singapore. Kaur focuses on the types of curriculum research conducted within Singapore that could be placed within the model proposed by Remillard and Heck. In addition, she indicates research reflected in some of the papers, specifically the paper by Confrey and colleagues, which would likely be impossible to conduct within her country.

The commentary by Pepin (2014), written from a European perspective, compares and contrasts the theoretical approach in the model by Remillard and Heck with the instructional didactic approach often used in the European tradition. Her discussion about e-books, which are likely to become more prominent in the coming years, provides important insights into challenges and issues related to researching the enactment of curriculum that is in electronic form.

\section{Concluding remarks}

The papers in this issue have provided varied perspectives on researching the enacted mathematics curriculum, with many papers including empirical evidence. In many countries, the term curriculum refers to the objectives and 
standards that teachers are responsible for teaching. In contrast, in the US the term curriculum may refer to the objectives and standards but is also often used synonymously with textbooks. Hence, this issue has provided insight on researching the enactment of textbooks from many perspectives analogous to those of the TIMSS framework.

We hope that the papers and the related commentaries in this issue will help continue conversations about curriculum research, particularly ways to research and document the enacted curriculum of the textbook. There is much that scholars can learn from each other by sharing research questions and methods of conducting, analyzing, and reporting curriculum/textbook research. We look forward to continuing discussions about this work with readers of this issue.

\section{References}

Begle, E. G. (1973). Some lessons learned by SMSG. Mathematics Teacher, 66, 207-214.

Confrey, J., Maloney, A. P., \& Corley, A. K. (2014). Learning trajectories: a framework for connecting standards with curriculum. ZDM - The International Journal on Mathematics Education, 46(5) (this issue). doi:10.1007/s11858-014-0598-7.

Fan, L. (2013). Textbook research as scientific research: towards a common ground on issues and methods of research on mathematics textbooks. ZDM - The International Journal on Mathematics Education, 45(5), 765-777.

Hirsch, C. R. (2007). Curriculum materials matter. In C. R. Hirsch (Ed.), Perspectives on the design and development of school mathematics curricula (pp. 1-5). Reston: National Council of Teachers of Mathematics.

Hunsader, P. D., Thompson, D. R., Zorin, B., Mohn, A. L., Zakrzewski, J., Karadeniz, I., et al. (2014). Assessments accompanying published textbooks: the extent to which mathematical processes are evident. ZDM - The International Journal on Mathematics Education, 46(5) (this issue). doi:10.1007/s11858-014-0570-6.

Huntley, M. A., \& Terrell, M. (2014). One-step and multi-step linear equations: a content analysis of five textbook series. ZDM - The International Journal on Mathematics Education, 46(5) (this issue). doi:10.1007/s11858-014-0627-6.

Kaur, B. (2014). Enactment of school mathematics curriculum in Singapore: whither research! ZDM - The International Journal on Mathematics Education, 46(5) (this issue). doi:10.1007/ s11858-014-0619-6.
National Council of Teachers of Mathematics. (1989). Curriculum and evaluation standards for school mathematics. Reston: National Council of Teachers of Mathematics.

National Council of Teachers of Mathematics. (2000). Principles and standards for school mathematics. Reston: National Council of Teachers of Mathematics.

Otten, S., \& Soria, V. M. (2014). Relationships between students' learning and their participation during enactment of middle school algebra tasks. ZDM - The International Journal on Mathematics Education, 46(5) (this issue). doi:10.1007/ s11858-014-0572-4.

Pepin, B. (2014). Re-sourcing curriculum materials: in search of an appropriate framework for researching the enacted mathematics curriculum. ZDM - The International Journal on Mathematics Education, 46(5) (this issue). doi:10.1007/s11858-014-0628-5.

Remillard, J. T., Harris, B., \& Agodini, R. (2014). The influence of curriculum material design on opportunities for student learning. ZDM - The International Journal on Mathematics Education, 46(5) (this issue). doi:10.1007/s11858-014-0585-z.

Remillard, J. T., \& Heck, D. J. (2014). Conceptualizing the curriculum enactment process in mathematics education. ZDM - The International Journal on Mathematics Education, 46(5) (this issue). doi:10.1007/s11858-014-0600-4.

Robitaille, D. F., Schmidt, W. H., Raizen, S. A., McKnight, C. C., Britton, E., \& Nicol, C. (1993). Curriculum frameworks for mathematics and science (TIMSS Monograph No. 1). Vancouver: Pacific Educational Press.

Schmidt, W. H., McKnight, C. C., \& Raizen, S. A. (1997). A splintered vision: an investigation of US science and mathematics education. Dordrecht: Kluwer.

Sears, R., \& Chávez, O. (2014). Opportunities to engage with proof: the nature of proof tasks in two geometry textbooks and its influence on enacted lessons. ZDM - The International Journal on Mathematics Education, 46(5) (this issue). doi:10.1007/ s11858-014-0596-9.

Thompson, D. R., \& Senk, S. L. (2014). The same geometry textbook does not mean the same classroom enactment. ZDM - The International Journal on Mathematics Education, 46(5) (this issue). doi:10.1007/s11858-014-0622-y.

Thompson, D. R., \& Usiskin, Z. (Eds.). (2014). Enacted mathematics curriculum: a conceptual model and research needs. Charlotte: Information Age.

Travers, K. J. (1992). Overview of the longitudinal version of the Second International Mathematics Study. In L. Burstein (Ed.), The IEA study of mathematics III: student growth and classroom processes (pp. 1-14). Oxford: Pergamon.

Valverde, G. A., Bianchi, L. J., Wolfe, R. G., Schmidt, W. H., \& Houang, R. T. (2002). According to the book: using TIMSS to investigate the translation of policy into practice through the world of textbooks. Dordrecht: Kluwer. 